\title{
14. FECAL PELLETS IN PLIOCENE ANTARCTIC DEEP-SEA SEDIMENTS, LEG 28, DSDP
}

\author{
A. G. Kaneps, Scripps Institution of Oceanography, La Jolla, California
}

\section{INTRODUCTION}

In the course of foraminiferal preparation on Leg 28 , small, bispherical objects were found in the $>63 \mu$ fraction of Pliocene sediments at two of the sites (266 and 274) drilled during this leg (Figure 1, Table 1). The objects are foraminifer size and were found to be acid soluble; they resemble small agglutinated foraminifers, but crushing of several specimens disclosed that they are not hollow. Subsequent examination on the scanning electron microscope revealed that they consist of comminuted diatom debris cemented by what appears to be calcite (Figure 2). As such, they are judged to be fecal pellets of a benthonic deposit feeder, although the calcite cement is unusual in this context. They are described here in view of their local abundance in noncalcareous sediments and their potential as stratigraphic markers in Antarctic sediments, in the absence of other fossils.

\section{DESCRIPTION}

The bilobate pellets are of uniform size and appearance. They are light brown in color and have a sugary surface texture when observed under the binocular microscope. The few measured specimens range from 0.263 to $0.270 \mathrm{~mm}$ in length. They consist of two appressed spheres, $0.17 \mathrm{~mm}$ in diameter, joined along a distinct suture. The suture is sharply incised in

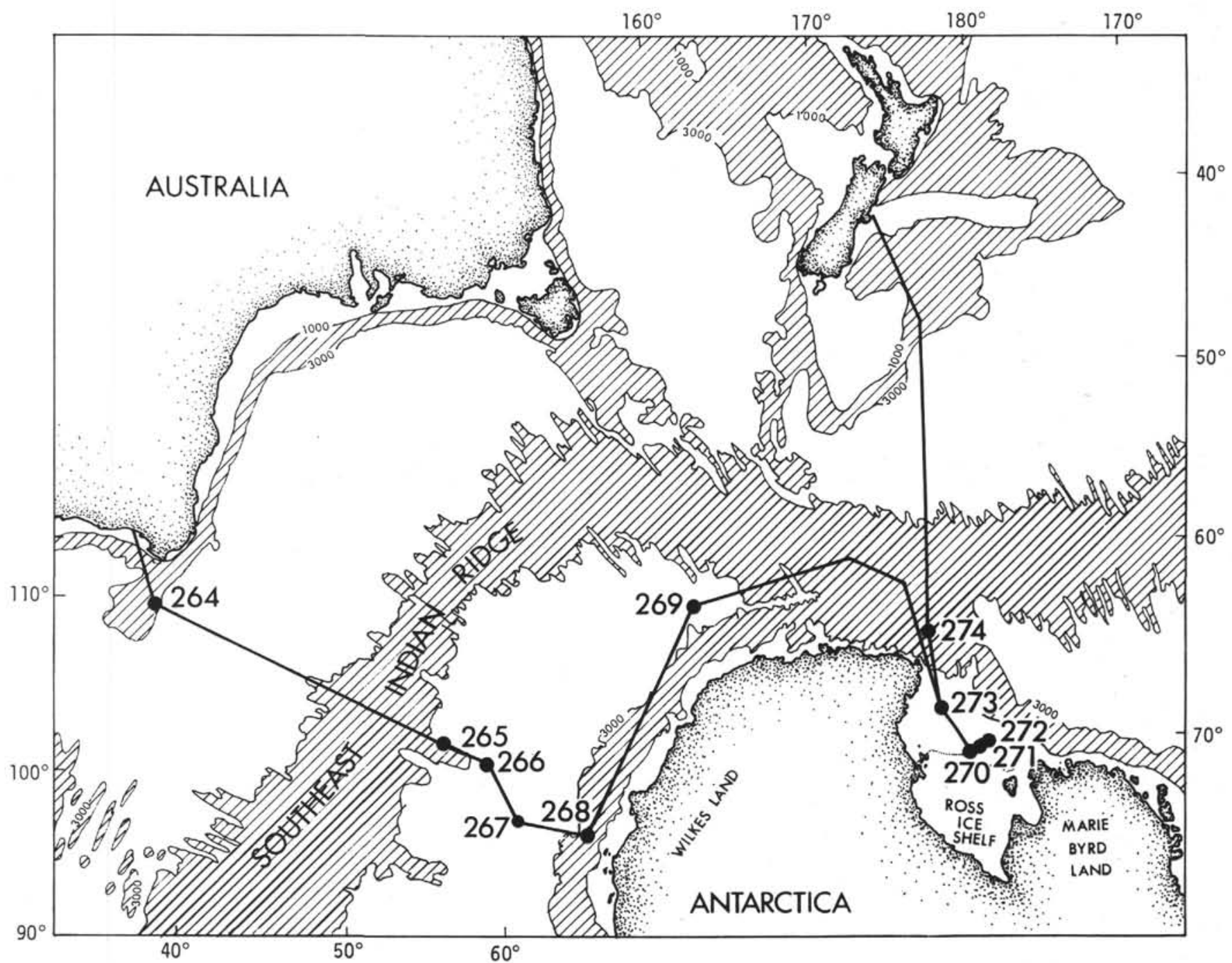

Figure 1. Location map showing Sites 266 and 274, Leg 28, Deep Sea Drilling Project. 
TABLE 1

Site Locations and Water Depths

\begin{tabular}{cccc}
\hline Site & Lat & Long & Water Depth (m) \\
\hline 266 & $56^{\circ} 24.13^{\prime} \mathrm{S}$ & $110^{\circ} 06.70$ ' & 4173 \\
274 & $68^{\circ} 59.81^{\prime} \mathrm{S}$ & $173^{\circ} 25.64^{\prime} \mathrm{E}$ & 3326 \\
\hline
\end{tabular}

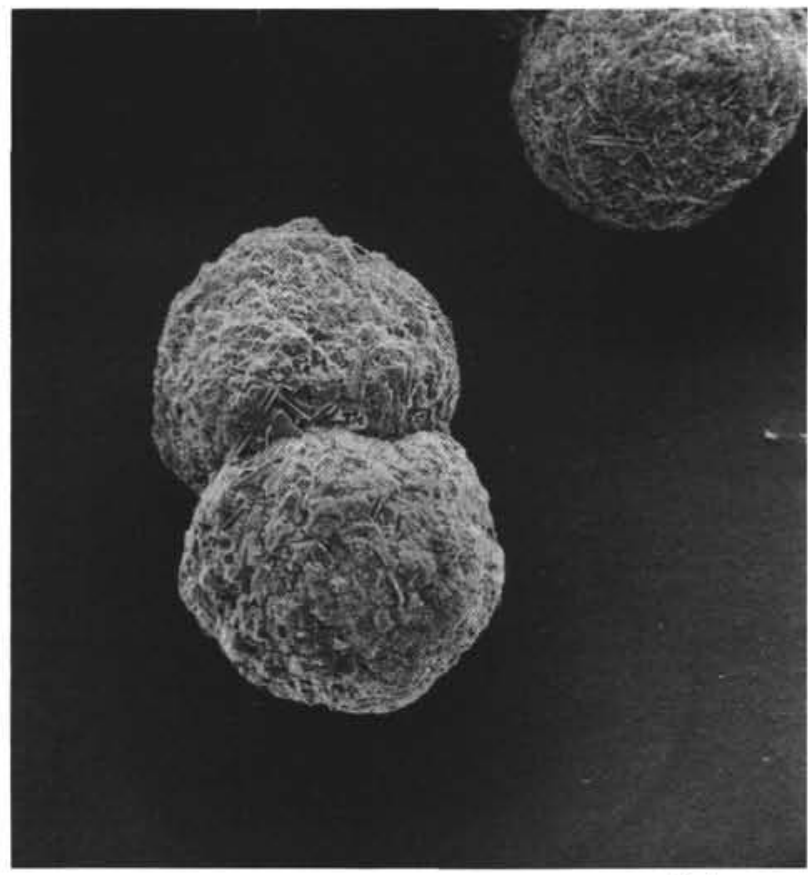

$0.1 \mathrm{~mm}$

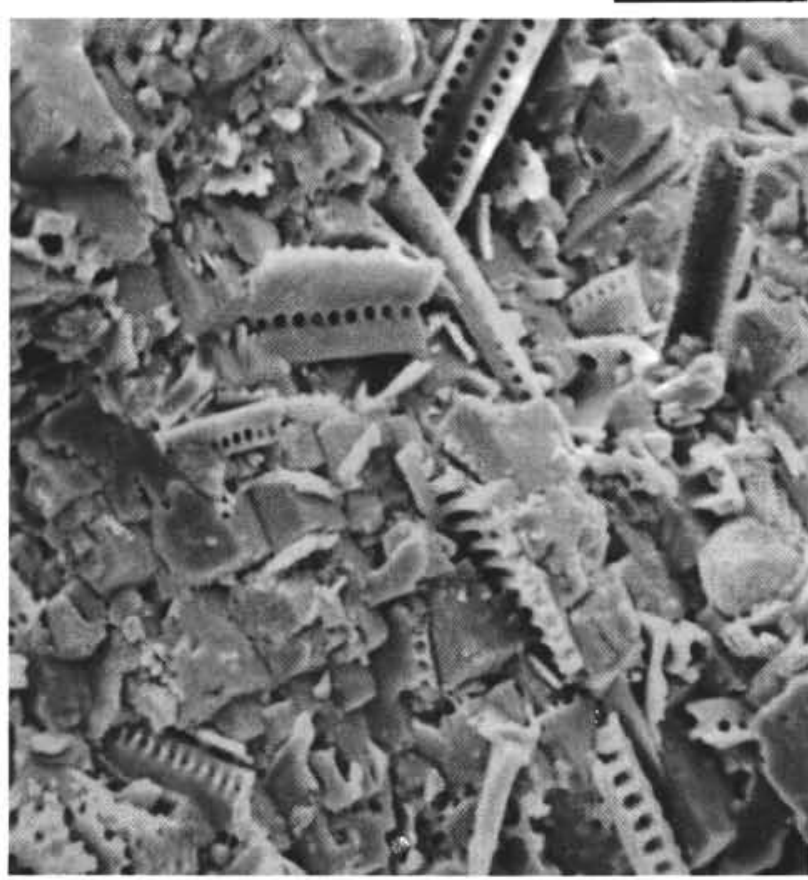

$0.01 \mathrm{~mm}$

Figure 2. (a) Fecal pellets (X193), Site 266, Core 8, Section 2, 80-82 cm; (b) Detail of middle portion of lower half of above (X1930), showing fragmented diatoms and well-crystallized calcite. the specimens from Site 266 (Figure 2) but less so in those from Site 274 (Figure 3). Occasional isolated spheres were seen, but these may be a result of breakage. The only departure from this uniform size and shape was found in Cores 7 and 8 of Site 266, where the pellets are generally spindly in shape, although typical forms also occur. Because a range of variation in the spindleshaped morphology was seen, these forms are judged to have undergone some dissolution of their calcite cement, with a resulting surface texture coarser than in the typical form. The extremely spindly forms resemble bundles of phillipsite crystals, although the original bilobate shape is still discernible.

\section{OCCURRENCE}

The pellets were found at two sites on Leg 28: Site 266 on the south flank of the Southeast Indian Ridge, and Site 274 on the lower continental rise north-northeast of Cape Adare. At Site 266 they occur in two distinct intervals in Cores 5 through 8 , with a barren interval from Section 4 of Core 6 to Section 2 of Core 7 (see Table 4 in Chapter 13 for details of abundance and distribution). Their abundance ranges from a few to several thousand specimens per 10 -cc sample. The enclosing sediments are siliceous ooze of lower Pliocene (lower Gilbert) age for the lower interval and lower upper Pliocene (upper Gilbert-Gauss) age for the upper interval (according to radiolarian and diatom biostratigraphy). At Site 274 they were seen in the core-catcher sample of Core 9 which, according to the radiolarians and diatoms, corresponds with the lower interval of occurrence at Site 266. They were not observed at the remainder of the Leg 28 sites, but this may be due to sampling gaps, hiatus, or terrigenous dilution at Sites 268 and 269.

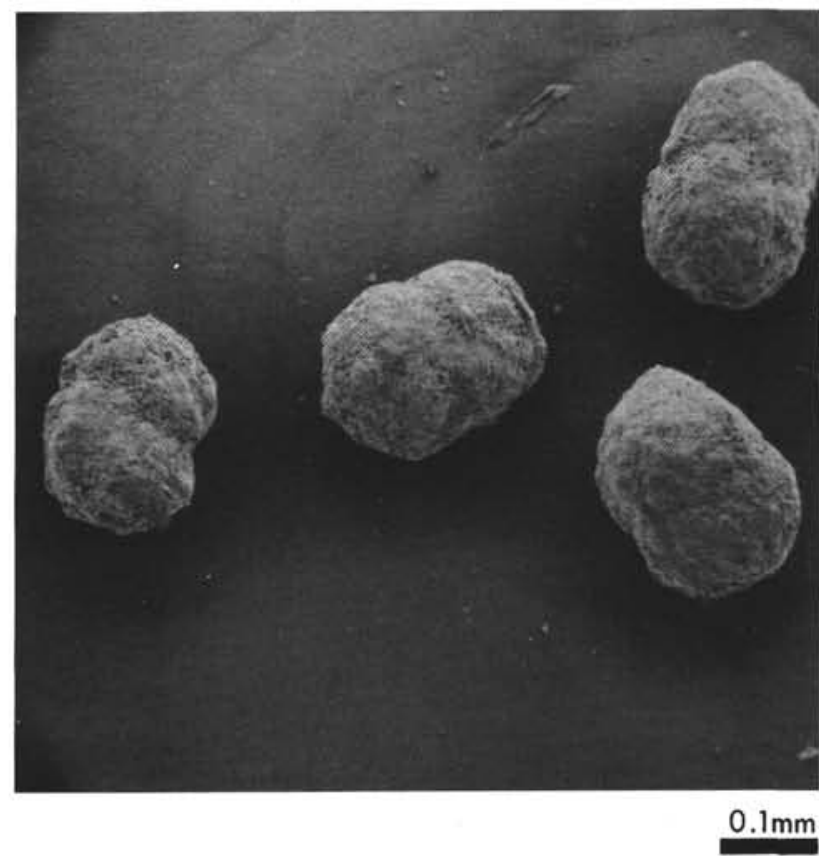

Figure 3. Fecal pellets (X95), Site 266, Core 9, core catcher. 


\section{SIGNIFICANCE}

The main significance of these fecal pellets at present lies in their potential as biostratigraphic markers in the Antarctic region, if their occurrence at a similar stratigraphic level at Sites 266 and 274 is any indication of their general distribution. Nothing as yet can be said about their paleoenvironmental significance. It is probable, however, that the present objects are the work of a benthonic deposit feeder. They resemble, in general, fecal pellets of various benthonic organisms, described by Moore (1939). Moreover, the fragmented nature of the diatoms suggests grinding by mouth parts or in the gut of a deposit feeder. In contrast, fecal pellets produced by present-day planktonic copepods are not coherent, consisting of undamaged diatom frustules enclosed by a thin membrane (Schrader, 1971).

The anomalous feature of the present fecal pellets is their well-crystallized calcite cement (see Figure 2). Calcite as a primary cement of fecal pellets has, as far as is known, not been reported, and it would seem more likely to be a product of diagenesis. Its source may be the thin film of pelagic detritus, which includes tests of foraminifers and nannoplankton, that covers the ocean floor even in areas underlain by carbonate-free sediments. A deposit feeder might ingest this material and incorporate it unaltered in its fecal matter. Subsequent recrystallization of this carbonate at depth in the sediment might then produce the calcite cemented pellets seen in Leg 28 material.

\section{ACKNOWLEDGMENTS}

The author expresses gratitude to T. Vallier, P. Worstell, L. F. Musich, and R. E. Boyce for provocative and fertile discussion of the contents of this paper.

\section{REFERENCES}

Moore, H. B., 1939. Faecal pellets in relation to marine deposits. In Trask, P. D. (Ed.), Recent marine sediments: Tulsa (Am. Assoc. Petrol. Geol.), p. 516-524.

Schrader, H. J., 1971. Fecal pellets: role in sedimentation of pelagic diatoms: Science, v. 174, p. 55-57. 